\title{
Inhibitory Effects of Astragalus Polysaccharide on Myocardial Apoptosis Induced by Hypoxia or Reoxygenation in Rats
}

\begin{abstract}
LAI WEI, YINGZHE LIU1 ${ }^{1}$ ZHIPING LIU, QICHAO MAO, NA SHI AND JIANFEI YANG ${ }^{*}$
Clinical Medical College of Heilongjiang University of Chinese Medicine, No. 24 Heping Road, Harbin 150040, ${ }^{1}$ Department of Endocrinology, The First Affiliated Hospital of Heilongjiang University of Chinese Medicine, ${ }^{2}$ Department of Cardiovascular Medicine, The First Affiliated Hospital of Heilongjiang University of Chinese Medicine, No. 26 Heping Road, Harbin 150040, Heilongjiang Province, China
\end{abstract}

Wei et al.: Astragalus Polysaccharide and Myocardial Apoptosis

\begin{abstract}
To explore the inhibitory effects of Astragalus polysaccharide on myocardial apoptosis induced by hypoxia/ reoxygenation in rats based on the high mobility group box $1 /$ toll-like receptor 4 /nuclear factor kappa $B$ signaling pathway. The hypoxia/reoxygenation injury model of $\mathrm{H9C2}$ myocardial cells was established and divided into control group, hypoxia/reoxygenation group, Astragalus polysaccharide group and high mobility group box 1 inhibitor group. Cell proliferation and apoptosis were detected by cell counting kit-8 assay and Annexin V-fluorescein isothiocyanate/propidium iodide double staining. The messenger RNA expressions of high mobility group box 1, toll-like receptor 4 and nuclear factor kappa $B$ were detected by quantitative reverse transcription polymerase chain reaction and the contents of tumor necrosis factor alpha, interleukin-1 $\beta$ and interleukin-6 were determined using enzyme-linked immunosorbent assay. Compared with control group, cell proliferation was significantly weakened, apoptosis was significantly enhanced and the messenger RNA expressions of high mobility group box 1, toll-like receptor 4 and nuclear factor kappa $B$ and the contents of tumor necrosis factor alpha, interleukin-1 $\beta$ and interleukin-6 significantly increased in hypoxia/reoxygenation group $(p<0.05)$. Compared with hypoxia/reoxygenation group, Astragalus polysaccharide group and high mobility group box 1 inhibitor group had significantly enhanced cell proliferation, weakened apoptosis and decreased messenger RNA expressions of high mobility group box 1, toll-like receptor 4 and nuclear factor kappa $B$ and contents of tumor necrosis factor alpha, interleukin-1 $\beta$ and interleukin- $6(p<0.05)$. Astragalus polysaccharide can repair the hypoxia/ reoxygenation injury of $\mathrm{H9C} 2$ myocardial cells, which may suppress apoptosis through inhibiting the high mobility group box 1/toll-like receptor 4/nuclear factor kappa B signaling pathway.
\end{abstract}

Key words: High mobility group box 1 , toll-like receptor 4, nuclear factor kappa B, Astragalus polysaccharide, hypoxia/reoxygenation, myocardial apoptosis

Myocardial ischemia reperfusion injury (MIRI) is irreversible injury caused by the recovery of blood perfusion after myocardial tissue ischemia, which often leads to decline in cardiac function, expansion of myocardial infarction area and ultimately heart failure, with a higher lethality rate ${ }^{[1,2]}$. The mechanism of MIRI is related to the production of oxygen free radicals, calcium overload, abnormal inflammatory response and apoptosis ${ }^{[3]}$. Astragalus polysaccharide (APS) is one of the main active components of dried roots of Astragalus membranaceus Bge. or Mongolia astragaloside, which is a kind of water-soluble polysaccharide obtained by extraction, concentration and purification, mixed by glucose, hexuronic acid, fructose, galactose and arabinose ${ }^{[4]}$. It possesses the anti-tumor, anti-virus, anti-oxidative stress and anti-

*Address for correspondence

E-mail: yangjianfei119@163.com

614 apoptosis effects, which can serve as an immune promoter or regulator ${ }^{[5,6]}$. It has been found that APS can alleviate myocardial damage in MIRI of animal models. The high mobility group box 1 (HMGB1)/tolllike receptor 4 (TLR4)/nuclear factor kappa B (NF-kB) signaling pathway can effectively interfere with MIRI through activating the inflammatory response $\mathrm{e}^{[7]}$. However, whether APS can inhibit MIRI by downregulating the HMGB1/TLR4/NF- $\mathrm{KB}$ signaling

\footnotetext{
This is an open access article distributed under the terms of the Creative Commons Attribution-NonCommercial-ShareAlike 3.0 License, which allows others to remix, tweak, and build upon the work non-commercially, as long as the author is credited and the new creations are licensed under the identical terms
}

Accepted 15 June 2021 Revised 24 February 2021

Received 20 November 2020 Indian J Pharm Sci 2021;83(3):614-617 
pathway has not been reported yet. In the present study, the primary cultured myocardial cells were subjected to hypoxia/reoxygenation $(\mathrm{H} / \mathrm{R})$ to simulate MIRI and the influence of APS on apoptosis of myocardial cells during H/R was observed through the HMGB1/TLR4/ $\mathrm{NF}-\kappa \mathrm{B}$ signaling pathway. The following materials were used: H9C2 myocardial cell lines (ATCC), APS (Changsha Green Health Biological Products Co., Ltd.), fetal bovine serum (FBS) (Hangzhou Sijiqing Bioengineering Materials Co., Ltd.), trypsin (Gibco, USA), Dulbecco's Modified Eagle Medium (DMEM) (Sigma, USA), bicinchoninic acid (BCA) protein quantification kits (Nanjing KeyGEN BioTECH Co., Ltd.), rabbit anti-HMGB1, TLR4 and NF-kB monoclonal antibodies (Abcam, USA), Annexin V-fluorescein isothiocyanate (FITC)/propidium iodide (PI) double staining kits (Takara, Dalian), enzymelinked immunosorbent assay (ELISA) kits (Wuhan Boster Biological Technology Co., Ltd.), carbon dioxide $\left(\mathrm{CO}_{2}\right)$ incubator and a Multiskan FC microplate reader (Thermo, USA), a clean bench (Suzhou AirTech Co., Ltd.), a low-temperature high-speed centrifuge (Eppendorf, Germany) and a transmission electron microscope (JEOL, Japan). Establishment of $\mathrm{H} / \mathrm{R}$ injury models ${ }^{[8]}$ is done. Myocardial cells in the logarithmic growth phase were inoculated in a 24-well plate. Upon reaching $85 \%$ confluence, the original medium was replaced with simple sugar-free medium. Then mixed gas of $95 \%$ nitrogen $\left(\mathrm{N}_{2}\right)$ and $5 \% \mathrm{CO}_{2}$ was injected and the cells were incubated at $37^{\circ}$ for $4 \mathrm{~h}$. The medium was replaced with DMEM containing $10 \%$ FBS and mixed gas of $95 \%$ air and $5 \% \mathrm{CO}_{2}$ was injected, followed by culture at $37^{\circ} \mathrm{C}$ for $12 \mathrm{~h}$. Grouping is done and the myocardial cells were randomly divided into control group (cells were cultured normally), model group (H/R group: H/R cells), experimental group (APS group: APS at a final concentration of $1 \mathrm{mg} / \mathrm{l}$ was added into $\mathrm{H} / \mathrm{R}$ cells at $30 \mathrm{~min}$ before modeling) and HMGB1 intervention group: (HMGB1 inhibitor group: HMGB1 inhibitor glycyrrhizin at a final concentration of $100 \mu \mathrm{g} / \mathrm{ml}$ was added into $\mathrm{H} / \mathrm{R}$ cells at $30 \mathrm{~min}$ before modeling). Detection of cell proliferation by cell counting kit-8 (CCK8) assay was carried out. The above cells were added with $10 \mu \mathrm{l}$ of CCK8 solution each well at 12, 24, 48 and $72 \mathrm{~h}$, respectively, with 3 replicates for each well and incubated in an incubator at $37^{\circ}$ for $2 \mathrm{~h}$. The absorbance at $450 \mathrm{~nm}$ was measured using a microplate reader. Detection of apoptosis via AnnexinV-FITC/PI double staining is done. At $24 \mathrm{~h}$ after modeling, $5 \times 10^{5}$ cells were centrifuged, washed with phosphate-buffered saline (PBS) and suspended with $500 \mu \mathrm{l}$ of binding buffer, followed by incubation with each $10 \mu \mathrm{l}$ of AnnexinV-FITC and PI for $30 \mathrm{~min}$ in the dark. Finally, apoptosis was detected by flow cytometry and analyzed using NovoExpress ${ }^{\mathrm{TM}}$ software. Detection of HMGB1, TLR4 and NF- $\kappa B$ messenger ribonucleic acid (mRNA) expressions by quantitative reverse transcription polymerase chain reaction (qRT-PCR) was carried out. After modeling, H9C2 cells were collected in each group, from which the total RNA was extracted by TRIzol and reversely transcribed into complementary deoxyribonucleic acid (cDNA), followed by amplification. The amplification system $(20 \mu l)$ included $10 \mu \mathrm{l}$ of SYBR Green Mix, $8 \mu \mathrm{l}$ of double-distilled water $\left(\mathrm{ddH}_{2} \mathrm{O}\right), 0.5 \mu \mathrm{l}$ of forward primers, $0.5 \mu \mathrm{l}$ of reverse primers and $1 \mu \mathrm{l}$ of cDNA template. The amplification conditions were as follows: predenaturation at $95^{\circ}$ for $5 \mathrm{~min}, 95^{\circ}$ for $30 \mathrm{~s}, 60^{\circ}$ for $10 \mathrm{~s}$, $72^{\circ}$ for $25 \mathrm{~s}, 40$ cycles in total. The relative expression level of mRNA was calculated using $2^{-\Delta \Delta C T}$. The primer sequences were as follows: HMGB1 F: 5'-ATCCATTGGTGATGTTGC-3', R: 5'-TCTTTTCATAGGGCTGCT-3'. TLR4 F: 5'-ATCCCTTATTCAACCA-3', R: 5'-TGTCTCCACAGCCACC-3'. NF-кB F: 5'-TGTTTCCССТCATCTTTCC-3', R: 5'-GTGGTATCTGTGCTTCTCTCC-3'. U6 F: 5'-CTCGCTTCGGCAGCACA-3', R: 5'-AACGCTTCACGAATTTGCGT-3'. Tumor necrosis factor alpha (TNF- $\alpha$ ), interleukin-1 beta (IL$1 \beta$ ) and interleukin-6 (IL-6) content was detected by ELISA. After modeling, the culture medium in the 24well plate was collected and detected according to the instructions of ELISA kits. The absorbance at $450 \mathrm{~nm}$ was measured using the microplate reader and the standard curve was plotted, based on which the content of inflammatory factors was calculated. SPSS16.0 software was used for statistical analysis and Graphpad 5.0 software was used for plotting. Numerical data were expressed as $\mathrm{n}(\%)$ and the comparison was conducted by $\chi^{2}$ test between two groups and performed by oneway analysis of variance among groups, $\mathrm{p}<0.05$ was considered statistically significant. Effect of APS on proliferation of H/R-injured cells was compared. The results of CCK8 assay showed that the cell proliferation was significantly weakened in $\mathrm{H} / \mathrm{R}$ group compared with that in control group $(\mathrm{p}<0.05)$, while it was significantly enhanced in APS group and HMGB1 inhibitor group compared with that in $\mathrm{H} / \mathrm{R}$ group $(p<0.05)$. Therefore, both APS and HMGB1 inhibitor can restore the proliferation ability of H/R-injured cells 
(fig. 1). Effect of APS on apoptosis of H/R-injured cells was compared. The results of flow cytometry revealed that the apoptosis rate was significantly higher in $\mathrm{H} / \mathrm{R}$ group than that in control group $(\mathrm{p}<0.05)$, while it was significantly lower in APS group and HMGB1 inhibitor group than that in $\mathrm{H} / \mathrm{R}$ group $(\mathrm{p}<0.05)$ (fig. 2$)$. It can be inferred that APS and HMGB1 inhibitor can inhibit the apoptosis of $\mathrm{H} / \mathrm{R}$-injured cells. Effects of APS on mRNA expressions of HMGB1, TLR4 and NF- $\kappa B$ in $\mathrm{H} / \mathrm{R}$-injured cells were compared. It was found from qRT-PCR that $\mathrm{H} / \mathrm{R}$ group had significantly higher mRNA expressions of HMGB1, TLR4 and NF- $\kappa$ B than control group $(p<0.05)$. APS group and HMGB1 inhibitor group had significantly lower mRNA expressions of HMGB1, TLR4 and NF- $\kappa B$ than $\mathrm{H} / \mathrm{R}$ group $(p<0.05)$ (fig. 3$)$. The above results demonstrate that APS and HMGB1 inhibitor can inhibit the mRNA expressions of HMGB1, TLR4 and NF- $\mathrm{KB}$ in H/Rinjured cells. Effects of APS on contents of TNF- $\alpha$, IL$1 \beta$ and IL- 6 in H/R-injured cells were compared. The results of ELISA showed that the contents of TNF- $\alpha$, IL- $1 \beta$ and IL- 6 in H/R group significantly rose compared with that in control group $(\mathrm{p}<0.05)$. The contents of TNF- $\alpha$, IL- $1 \beta$ and IL- 6 in APS group and HMGB1 Inhibitor group significantly declined compared with that in $\mathrm{H} / \mathrm{R}$ group $(\mathrm{p}<0.05)$ (fig. 4). The above findings demonstrate that the release of inflammatory factors TNF- $\alpha$, IL-1 $\beta$ and IL- 6 in H/R-injured cells can be inhibited by APS and HMGB1 inhibitor. MIRI, a major problem in the clinical prevention and treatment of ischemic heart disease, involves many mechanisms, including inflammatory response, oxidative stress, apoptosis and autophagy. The activation of inflammatory response in vivo causes further damage to myocardial cells, worsening apoptosis and increasing myocardial infarction area ${ }^{[9]}$. APS is able to resist inflammation, oxidation and tumor, which cannot only enhance the immune functions of $\mathrm{T}$ cells and $\mathrm{B}$ cells, but also strengthen chemosensitivity and kill tumor cells ${ }^{[10,11]}$. In

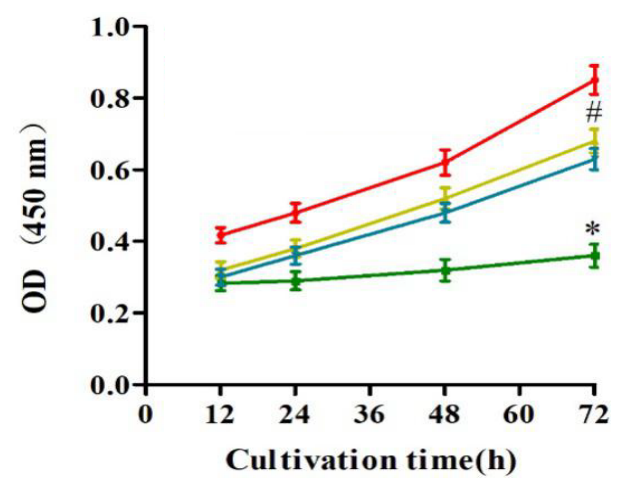

Fig. 1: Effect of APS on proliferation of $H / R$-injured cells, ${ }^{*} \mathbf{p}<\mathbf{0 . 0 5}$ vs. control group, $\# \mathbf{p}<\mathbf{0 . 0 5}$ vs. $\mathrm{H} / \mathbf{R}$ group

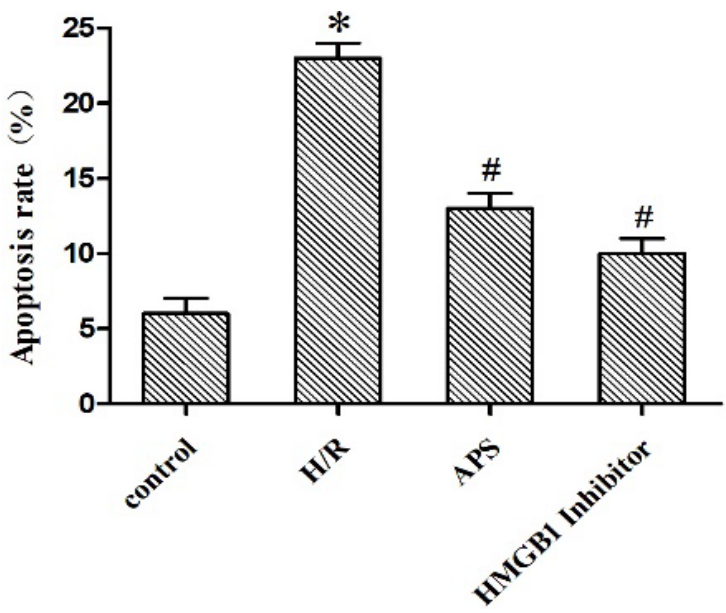

Fig. 2: Effect of APS on apoptosis of $H / R$-injured cells, *p<0.05 vs. control group, ${ }^{\#} \mathbf{p}<0.05$ vs. $H / R$ group

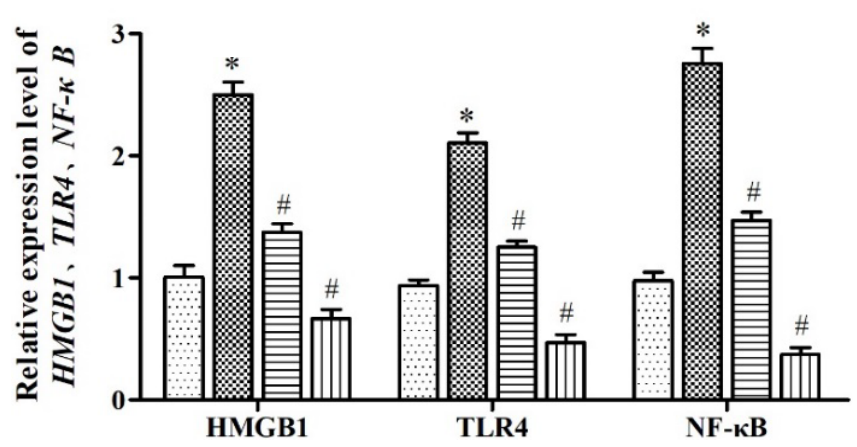

Fig. 3: Effects of APS on mRNA expressions of HMGB1, TLR4 and $N F-\kappa B$ in $H / R$-injured cells, ${ }^{*} p<0.05$ vs. control group, ${ }^{\#} \mathbf{p}<\mathbf{0 . 0 5}$ vs. $\mathrm{H} / \mathrm{R}$ group

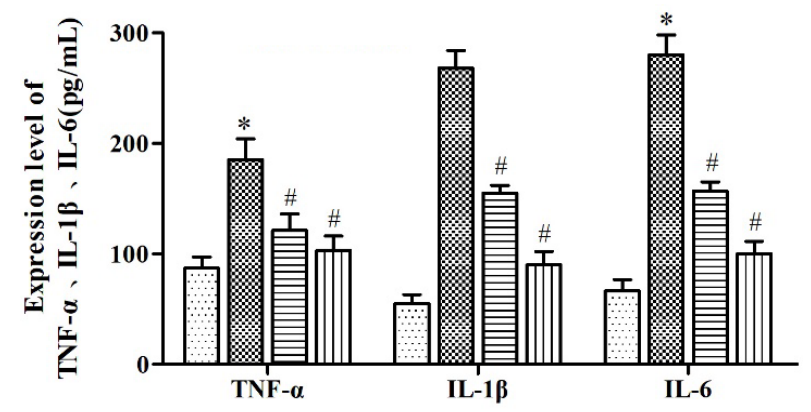

Fig. 4: Effects of APS on contents of TNF- $\alpha$, IL-1 $\beta$ and IL-6 in $H / R$-injured cells, ${ }^{*} \mathbf{p}<0.05$ vs. control group, ${ }^{*} p<0.05$ vs. $H / R$ group

recent years, it has been found that APS inhibits autophagy and improves myocardial function through suppressing the expression of mitogen-activated protein kinase kinase kinase kinase 3 (MAP4K3) and mammalian target of rapamycin (mTOR) signaling pathway ${ }^{[12]}$. In the present study, the H/R-injured cells had weakened proliferation and enhanced apoptosis, while both proliferation and apoptosis were restored to a certain extent after treatment with APS or HMGB1 inhibitor. It can be seen that APS and HMGB1 inhibitor 
have a similar effect of repairing $H / R$ injury and inhibiting apoptosis. HMGB1 can bind to DNA and be released by myocardial cells with ischemic necrosis, thereby inducing the inflammatory response, which is an early mediator of inflammatory response in MIRI ${ }^{[13]}$. After MIRI occurs, TLR4 will be activated, activating downstream NF- $\kappa \mathrm{B}$ protein. Then NF- $\kappa \mathrm{B}$ will enter the cell nucleus to activate the transcriptional activity of inflammatory factors TNF- $\alpha$, IL- $1 \beta$ and IL-6, worsening the inflammatory response ${ }^{[14]}$. Cai et al. ${ }^{[15]}$ found that geniposide inhibited the release of inflammatory factors TNF- $\alpha$, IL-1 $\beta$ and IL-6 in H/R-injured myocardial cells through the TLR4/NF- $\kappa \mathrm{B}$ signaling pathway. In the present study, the expressions of HMGB1, TLR4 and $N F-\kappa B$ and the contents of TNF- $\alpha$, IL- $1 \beta$ and IL- 6 in H/R-injured myocardial cells were obviously higher in $H / R$ group than those in control group, while the HMGB1/TLR4/NF- $\kappa \mathrm{B}$ signaling pathway and expressions of inflammatory factors in H/R-injured myocardial cells were suppressed in APS group and HMGB1 inhibitor group. The above findings suggest that APS and HMGB1 inhibitor have a similar effect of repairing H/R-injured myocardial cells, whose mechanism may be related to the inhibition on HMGB1/ TLR4/NF- $\kappa B$ signaling pathway. In conclusion, APS is able to repair the H/R injury of H9C2 myocardial cells, which may suppress apoptosis through inhibiting the HMGB1/TLR4/NF- $\kappa B$ signaling pathway. This study offers a new direction to the treatment of MIRI.

\section{Author's contributions:}

Lai Wei and Yingzhe Liu contributed equally to this study.

\section{Acknowledgements:}

This study was financially supported by Heilongjiang University of Chinese Medicine Foundation-Doctoral Innovation Fund Project (No. 2018bs09).

\section{Conflicts of interest:}

The authors declared no conflict of interest.

\section{REFERENCES}

1. Ibanez B, Heusch G, Ovize M, Van de Werf F. Evolving therapies for myocardial ischemia/reperfusion injury. $\mathrm{J}$ Am Coll Cardiol 2015;65(14):1454-71.

2. Wang S, Zhu Y, Qiu R. Shikonin protects H9C2 cardiomyocytes against hypoxia/reoxygenation injury through activation of PI3K/Akt signaling pathway. Biomed Pharmacother 2018;104:712-7.

3. Liu J, Sui H, Zhao J, Wang Y. Osmotin protects H9c2 cells from simulated ischemia-reperfusion injury through AdipoR1/ PI3K/AKT signaling pathway. Front Physiol 2017;8:611.

4. Zheng Y, Ren W, Zhang L, Zhang Y, Liu D, Liu Y. A review of the pharmacological action of Astragalus polysaccharide. Front Pharmacol 2020;11:349.

5. Lu L, Huang YF, Chen DX, Wang M, Zou YC, Wan H, et al. Astragalus polysaccharides decrease muscle wasting through Akt/mTOR, ubiquitin proteasome and autophagy signalling in 5/6 nephrectomised rats. J Ethnopharmacol 2016;186:125-35.

6. Yan-Feng H, Lu L, Da-Jian Z, Wang M, Yin Y, De-Xiu C, et al. Effects of Astragalus polysaccharides on dysfunction of mitochondrial dynamics induced by oxidative stress. Oxid Med Cell Longev 2016;2016.

7. Dong LY, Chen F, Xu M, Yao LP, Zhang YJ, Zhuang Y. Quercetin attenuates myocardial ischemia-reperfusion injury via downregulation of the HMGB1-TLR4-NF- $\mathrm{BB}$ signaling pathway. Am J Transl Res 2018;10(5):1273-83.

8. Yu D, Li M, Tian Y, Liu J, Shang J. Luteolin inhibits ROSactivated MAPK pathway in myocardial ischemia/reperfusion injury. Life Sci 2015;122:15-25.

9. Toldo S, Mauro AG, Cutter Z, Abbate A. Inflammasome, pyroptosis and cytokines in myocardial ischemia-reperfusion injury. Am J Physiol Heart Circ Physiol 2018;315(6):H155368.

10. Zeng P, Li J, Chen Y, Zhang L. The structures and biological functions of polysaccharides from traditional Chinese herbs. Prog Mol Biol Transl Sci 2019;163:423-44.

11. Shan H, Zheng X, Li M. The effects of Astragalus membranaceus active extracts on autophagy-related diseases. Int J Mol Sci 2019;20(8):1904-11.

12. Chuang HC, Tan TH. MAP4K3/GLK in autoimmune disease, cancer and aging. J Biomed Sci 2019;26(1):1-8.

13. Sun N, Wang H, Wang L. Protective effects of ghrelin against oxidative stress, inducible nitric oxide synthase and inflammation in a mouse model of myocardial ischemia/ reperfusion injury via the HMGB1 and TLR4/NF- $\mathrm{BB}$ pathway. Mol Med Rep 2016;14(3):2764-70.

14. Chen H, Zhang RQ, Wei XG, Ren XM, Gao XQ. Mechanism of TLR-4/NF- $\kappa$ B pathway in myocardial ischemia reperfusion injury of mouse. Asian Pac J Trop Med 2016;9(5):503-7.

15. Cai ZH, Wang J, Zheng YP. Inhibitory effects of geniposide on release of inflammatory factors TNF- $\alpha$, IL-1 $\beta$ and IL- 6 in $\mathrm{H} / \mathrm{R}$-injured myocardial cells via the TLR4/NF- $\kappa \mathrm{B}$ signaling pathway. J Guangzhou Univ Tradit Chin Med 2016;33(2):234-7. 